\title{
MICROSTRUCTURE EVOLUTION DURING SEMI-SOLID PROCESSING OF MAGNESIUM AZ91D
}

\author{
M.T. Shehata, V. Kao and E. Essadiqi \\ Materials Technology Laboratory/CANMET, Natural Resources Canada \\ 568 Booth Street, Ottawa, Ontario, Canada K1A 0G1 \\ C.A. Loong and C-Q Zheng \\ Industrial Materials Institute, National Research Council Canada \\ 75 de Mortagne, Boucherville, Quebec, Canada J4B 6Y4
}

Semi-solid forming is a relatively new process whereby an alloy with thixotropic characteristics at a temperature between solidus and liquidus is formed (cast or forged) into a component in a mould or die. This technology is based on research originally carried out at MIT in the 1970s on rheological properties of semi-solid metals subjected to mechanical stirring. By not starting with a super-heated melt as in conventional liquid pressure die casting, semi-solid die-casting offers distinct advantages such as low cycle time, less porosity and shrinkage because of non-turbulent flow and less volume fraction of liquid, improved die life and significantly better mechanical properties. On the other hand, by not starting with a solid metal as in conventional forging, semi-solid forging offers a distinct advantage of much less load required to form the part as well as the possibility of forging to the final shape in one step.

The success or failure in the production of a component largely depends on the temperature uniformity and microstructural homogeneity of the semi-solid thixotropic feedstock material prior to the forming operation. This paper describes results of work related to (1) the preparation of AZ91D feedstock by electro-magnetic stirring combined with superheat reduction, (2) reheating of this material by induction to the semi-solid state with thixotropic properties, (3) semi-solid die-casting of box-like components and (4) the semi-solid forging of a disc-like component. The reheating was carried out in a single induction coil programmed to provide variable power input such that a low temperature gradient and a minimal liquid metal segregation in the billet feedstock were achieved. The microstructure was monitored throughout the various stages of processing to achieve the desired semi-solid microstructure for successful forming operation.

The paper describes the evolution of the microstructure from preparation of feed stock material, during reheating and forming operations. Electromagnetic stirring combined with super heat reduction is shown to have a significant role in breaking up the dendritic structure to a rosette structure during the solidification of melt to prepare the desired feedstock material (Figure 1). Upon reheating to the semi-solid state, the rosette structure transform to a globular structure, which enables an easy gliding of the solid alpha-phase particles in the liquid phase during the forming operation (Figure 2) and hence, leading to a successful semi-solid die-casting and forging to the final component. 


\section{REFERENCES}

1. M.C. Flemings, "Behavior of Metal Alloys in the Semi-Solid State", Metallurgical Transaction, Volume A22, 952-981, May 1991.

2. M. T. Shehata, V. Kao, E. Essadiqi, C.A., Loong and C-Q Zheng, "Production and Die Casting of Semi-Solid Magnesium Alloy AZ91D”, 2002 SAE.

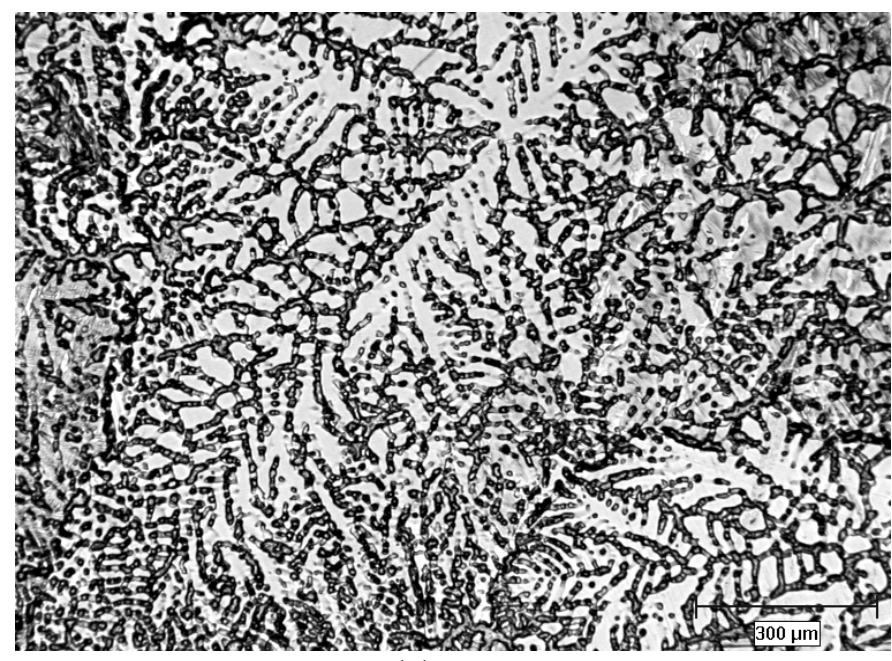

(a)

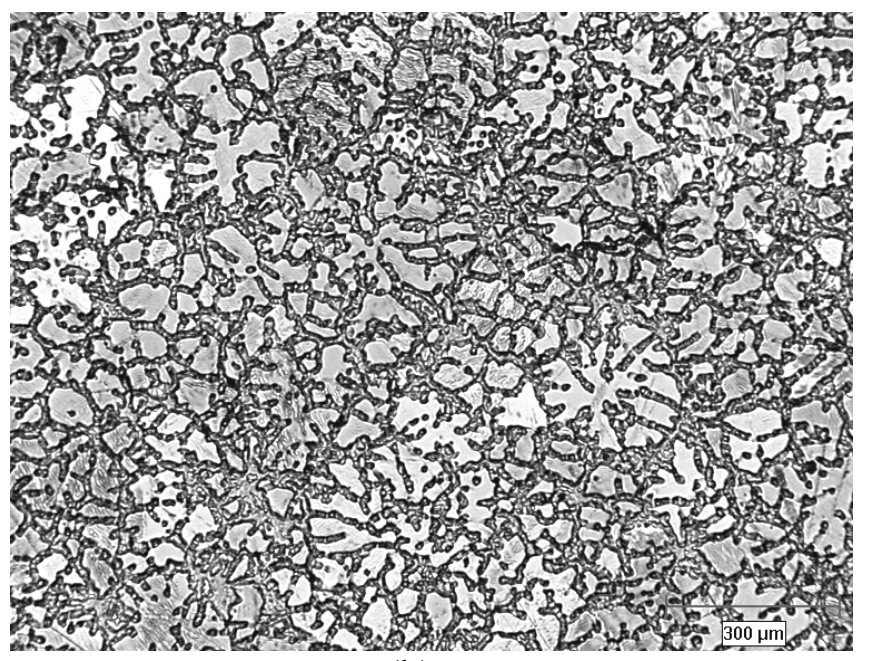

(b)

Figure 1. Microstructure of laboratory as-cast thixotropic feedstock AZ91D (a) without electromagnetic stirring (dendritic structure) and (b) with electro-magnetic stirring where dendrites are broken down to smaller rosettes.

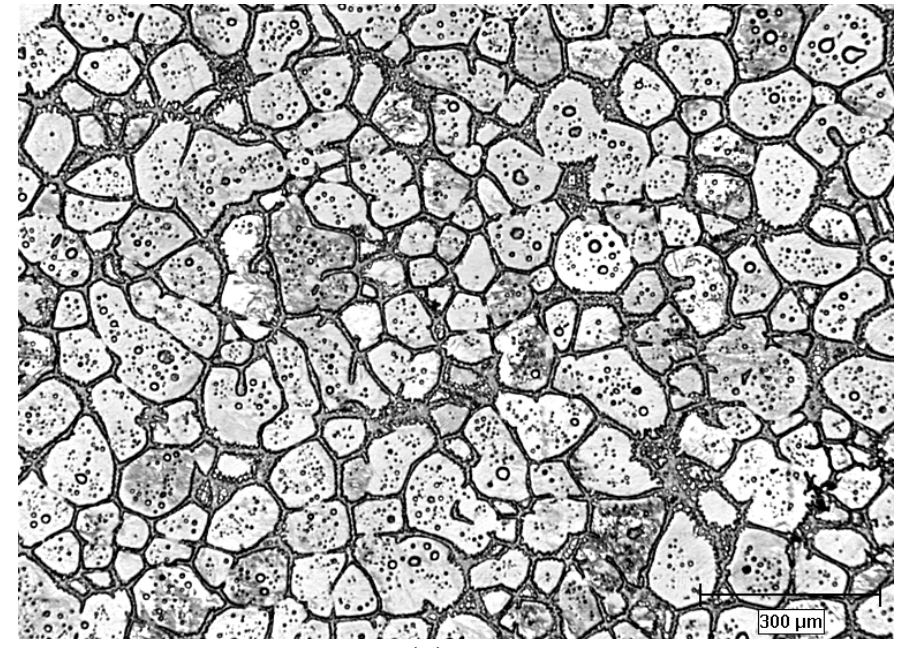

(a)

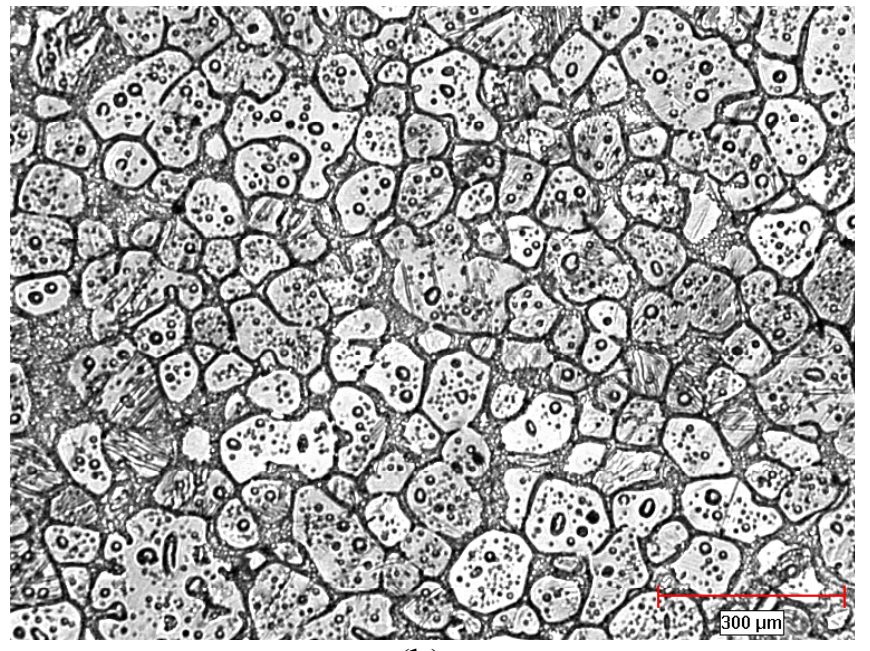

(b)

Figure 2. Microstructure of laboratory prepared AZ91D (a) after heating to $580^{\circ} \mathrm{C}$ and holding for 90 seconds and (b) after semi-solid forging into the final part. 